\title{
SCREENING OF $\alpha$-GLUCOSIDASE INHIBITORS FROM TERMINALIA CATAPPA L. FRUITS USING MOLECULAR DOCKING METHOD AND IN VITRO TEST
}

\author{
BINA LOHITA SARI ${ }^{a, b *}$, ABDUL MUN'IMa , ARRY YANUAR ${ }^{a}$, REZI RIADHIa \\ aFaculty of Pharmacy, Universitas Indonesia, Indonesia, Kampus UI Depok 16424, West Java, Indonesia, bStudy Programe of Pharmacy, \\ Universitas Pakuan, PO Box 452 Bogor 16143, West Java, Indonesia
}

Email: binalohitasari@yahoo.co.id

Received: 20 Aug 2016 Revised and Accepted: 15 Oct 2016

\begin{abstract}
Objective: Terminalia catappa L. (T. catappa L.) fruit has inhibitory activity on $\alpha$-glucosidase, therefore, can be a potential natural source for the treatment of type II diabetes mellitus. Inhibitory activity of ethanol fruit extract with $\mathrm{IC}_{50} 3.02 \mu \mathrm{g} / \mathrm{ml}$ was the strongest inhibition when compared with 54 medicinal plants used as an antidiabetic agent in Indonesia. This project was aimed to find the active compound from T. catappa L. fruit using molecular docking, identification ethyl acetate subfraction using TLC and GC-MC, determine in vitro test on $\alpha$-glucosidase inhibitory activity from ethyl acetate extract and subfraction.
\end{abstract}

Methods: Molecular docking using AutoDock 4.2 was performed to predict the binding modes of $\alpha$-glucosidase enzyme from Saccharomyces cereviciae with 13 chemical constituents of T. catappa. $\alpha$-Glucosidase enzyme was obtained from Protein Data Bank (PDB code: 3A4A). Acarbose, voglibose and miglitol were used as standards. Docking result determines the highest binding energy $(\Delta \mathrm{G})$ and inhibition constants (Ki) as an active compound. Visualization of amino acid residues around the active compound was identified with PyMOL and LigPlot. Screening of active compound was carried out by T. catappa L. fruit remaceration extraction use hexane and ethyl acetate. Ethyl acetate extract was separated on silica gel column chromatography using n-hexane, ethyl acetate and methanol sequentially based on polarity of each solvent. Identification of an active compound from ethyl acetate sub fractions using TLC and GC-MS method. The inhibitory activity of the active compound of $\alpha$-glucosidase was determined with in vitro test using $\alpha$-glucosidase enzyme.

Results: The highest binding energy and inhibition constant is $\beta$-sitosterol with $\Delta \mathrm{G}-10.61 \mathrm{kcal} / \mathrm{mol}$ and Ki $0.02 \mu \mathrm{M}$. The ligand was situated around of 18 amino acid residues. Ethyl acetate subfractions A, B and C showed that subfraction B contains similar spot characteristic and Rf value ( 0.42 ) with $\beta$-Sitosterol standard. Identification with GC-MS gave $\beta$-sitosterol acetate and sitostenone. Redocking process of $\beta$-sitosterol acetate and sitostenone showed $\Delta \mathrm{G}-11.14 \mathrm{kcal} / \mathrm{mol}$ and $-9.79 \mathrm{kcal} / \mathrm{mol}$ with $\mathrm{Ki} 0.01 \mu \mathrm{M}$ and $0.07 \mu \mathrm{M}$ respectively. In vitro test of acarbose, ethyl acetate extract and subfraction B gave $\mathrm{IC}_{50} 17.52 ; 192.51$ and $296.28 \mu \mathrm{g} / \mathrm{ml}$.

Conclusion: Three steroids that are $\beta$-sitosterol, $\beta$-sitosterol acetate and sitostenone were the active compounds responsible for $\alpha$-glucosidase inhibitory activity of T. catappa L. fruit. According to the in vitro test, ethyl acetate extract has stronger $\alpha$-glucosidase inhibitory activity than ethyl acetate subfraction $B$.

Keywords: $\alpha$-glucosidase inhibitor, T. catappa L., $\beta$-sitosterol, Molecular docking

(C) 2016 The Authors. Published by Innovare Academic Sciences Pvt Ltd. This is an open access article under the CC BY license (http://creativecommons.org/licenses/by/4. 0/]

DOI: http://dx.doi.org/10.22159/ijpps.2016v8i12.14800

\section{INTRODUCTION}

Diabetes mellitus (DM) is a metabolic disorder with hyperglycemia and glucose intolerance, due to insulin deficiency, impaired effectiveness of insulin action, or both [1]. One of therapeutic approaches for treating diabetes is to control the postprandial hyperglycemia by preventing the activity of $\alpha$-glucosidase, an enzyme involved in the digestion of carbohydrates. $\alpha$-glucosidase mainly produced in the epithelial mucosa of small intestine cleaves glycosidic bonds in complex carbohydrate to release absorbable monosaccharides. Therefore, $\alpha$-glucosidase inhibitors could be an attractive therapeutic treatment in type 2 diabetic patients [2]. The use of natural sources for the treatment of diabetes mellitus has gained importance throughout the world [3]. There are many plants in Indonesia can serve as a source for searching of anti diabetic agent with inhibition against $\alpha$-glucosidase [4].

T. catappa L., is a large tropical tree belongs to Combretaceae family. The plant grows in the Universitas Indonesia yard. It is well known as Indian almond fruit or 'Ketapang' in Indonesian. The selection of fruit is to utilize at harvest time and the fruit is reported has a strong inhibitory effect on $\alpha$-glucosidase. Petroleum ether, methanol, and aqueous extracts of this fruit demonstrated a significant antidiabetic activity at a dose $1 / 5$ of their lethal dose $(68 \mathrm{mg} / \mathrm{kg}, 40 \mathrm{mg} / \mathrm{kg}$ and $42 \mathrm{mg} / \mathrm{kg}$ per day p. o) [5]. Inhibitory activity of ethanol fruit extract with $\mathrm{IC}_{50} 3.02 \mu \mathrm{g} / \mathrm{ml}$ was the strongest inhibition when compared with 54 medicinal plants used as an antidiabetic agent in Indonesia.
Previous studies reveal that T. catappa L. fruit in common contains alkaloid, terpen, tannin, saponin, glycoside, anthraquinone [4]. The chemical compounds responsible for inhibiting the activity of the enzyme have not been known clearly.

In drug discovery research, the most appropriate strategy is screening compounds using computational approaches. This approaches, such as in silico molecular docking, can be used to determine in of a compound by predicting how a small molecule or ligand binds to macromolecule to produce stable conformation. There is a wide range of available software packages for docking simulations e. g. AutoDock, FlexX, and GOLD. All of them are based on the same fundamental principle of achieving an optimized conformation of both protein and ligand, in which the energy of the overall system is minimized. The important interaction parameter of ligands with the protein to be evaluated in this research is binding energy $(\Delta \mathrm{G})$ and inhibition constant (Ki) [6-7]. To predict the protein structure, homology modeling is commonly used because it is the easiest one [8].

The protein target was $\alpha$-glucosidase enzyme from $S$. cereviciae yeast. Screening of $\alpha$-glucosidase inhibitor was investigated on $T$. catappa fruit sub fraction resulted from ethyl acetate extract purification. Identification of compounds by Gas ChromatographyMass Spectrometry (GC-MS) presence bioactive compound. This compound predicted the same ligand with the docking result. The in vitro assay of $\alpha$-glucosidase inhibition use $\alpha$-glucosidase enzyme from $S$. cereviciae. Combined in silico and in vitro analysis showed an 
accurate result of bioactive compound in T. catappa fruit as inhibitor $\alpha$-glucosidase. The aim of this study was aimed to find the active compound from T. catappa L. fruit using molecular docking, identification ethyl acetate subfraction using TLC and GC-MC, determine in vitro test on $\alpha$-glucosidase inhibitory activity from ethyl acetate extract and subfraction.

\section{MATERIALS AND METHODS}

\section{Molecular docking}

Personal computer with Windows 7®64-bit operating system, Quad Core processor (Intel Core ${ }^{\mathrm{TM}}$ ), CPU (Central Processing Unit) Q8200 @ $2.33 \mathrm{GHz}$ (Intel Core ${ }^{\mathrm{TM}}$ ), and RAM (Random Access Memory) memory $4.00 \mathrm{~GB}$ was used to run the molecular docking process. SWISS-MODEL (http://swissmodel. expasy. org) for homology modeling [9], PROCHECK for evaluating the 3D model structure [10], AutoDock4.2 (developed by The Scripps Research Institute, USA) for molecular docking process, AutoDockTools (ADT) version 1.5.2 was employed as the graphical-user interface (GUI) to perform AutoDock [11]. Open Babel (downloaded from http://openbabel. org), to convert the molecule format throughout the research), LigPlot version 4.4.2 and PyMOL (developed by DeLano Scientific LLC, USA) was used to produce pictures, Antechamber and tLeap integrated with Amber Tools.

\section{Preparation of macromolecules}

The 3D structure of the $\alpha$-glucosidase model was constructed using homology modeling methods based on the crystal structure of the $S$. cereviciae $\alpha$-glucosidase MAL12 (Swiss-Prot code: P53341) and $S$. cereviciae isomaltase (PDB code: $3 \mathrm{~A} 4 \mathrm{~A}$ ). This model was conducted by SWISS-MODEL program obtained QMEAN (Qualitative Model Energy ANalysis) Z-score. Validation of protein structure and model of verifying the parameter like Ramachandran plot. The Plot calculation was done with PROCHECK program. The active site was defined as 8 amino acid residues: Asp69, His112, Arg213, Asp215, Glu277, His351, Asp352 and Arg442 [12].

\section{Preparation of ligands}

Acarbose, miglitol, and voglibose were used as standards [13] Suspected compounds from T. catappa which were already known from different references were shown in table 1 [14-16]. The 3D structure of the ligands was downloaded from the database such as ZINC, PubChem, or ChemDB. Ligands structure was optimized by bound charge correction. Minimized process by steepest descent and conjugate gradient. The process was performed using Antechamber and tLeap software integrated with Amber Tools. The results were restored as a pdb file.

Table 1: T. catappa $\mathrm{L}$. fruit compounds

\begin{tabular}{lll}
\hline Steroid & Polyphenol & Anthocyanin \\
\hline $\begin{array}{l}\text { 3-sitosterol, } \\
\text { daucosterol }\end{array}$ & $\begin{array}{l}\text { 1,3,6-tri-O-galloyl- } \beta \text {-D-glucose, corilagin, 3,6-digaloylglucose, } \beta \text {-glucogaline, ellagic acid, } \\
\text { brevifoline, shikimic acid, } \\
\text { gallic acid, quinic acid, chebulic acid }\end{array}$ \\
\hline
\end{tabular}

\section{Docking of ligands and $\alpha$-glucosidase volume grid}

The $\mathrm{x}, \mathrm{y}, \mathrm{z}$-coordinate of the center grid box was-21.727;-6.323;-5.28, volume of the grid was $70 \times 70 \times 80 \AA$ and the spacing was $0.375 \AA$. Docking parameters are genetic algorithm (GA), number of GA run was 100 and the output was chosen to be written as Lamarckian GA (LGA). Docking simulations were run under PuTTy interface based on LGA with long speed category, 25,000,000 times. Clustering tolerance for the root mean square deviation (rmsd) was $0.5 \AA$ with 100 times docking runs. Two parameters were calculated using Autodock Tools: that are binding energy $(\Delta G)$ and inhibition constant (Ki) [17]. Compounds with lowest $\Delta \mathrm{G}$ and Ki was predicted as the most potent $\alpha$-glucosidase inhibitors. H-bond interactions between ligand and surrounding amino acid were visualized and calculated with PyMOL and Ligplot. Residues that lie within $4 \AA$ around unit area that interacts with it through their side chain were considered as active site residues [18].

\section{Collection of plant material}

T. catappa L. fruits were collected (July-August, 2013) from Universitas Indonesia yard at Depok, West Java, Indonesia. Geographic location-between $06^{\circ} 20^{\prime} \mathrm{S}$ latitude- $06^{\circ} 21^{\prime} \mathrm{S}$ latitude and $106^{\circ} 49^{\prime} \mathrm{E}$ longitude-106 ${ }^{\circ} 51^{\prime}$ E longitude. The plant was identified by The Indonesian Academy of Sciences (voucher specimen number $1821 /$ IPH.3/KS/V/2014). The whole part of fruit was used in this study. The collected fruits were shade dried and finely powdered.

\section{Chemicals and reagents}

Enzyme $\alpha$-Glucosidase from Saccharomyces cerevisiae and $\mathrm{p}$ nitrophenyl- $\alpha$-D-glucopyranoside (pNPG) Code C-30358-00 were purchased from Sigma-Aldrich Company Ltd, (St. Louis, USA). Dimethyl sulphoxide (DMSO), bovine serum albumin (BSA), sodium carbonate, sodium hydroxide, silica gel $\mathrm{G} 6 \mathrm{~F}_{254}$ and TLC silica gel 60 $\mathrm{F}_{254}$ were purchased from E. Merck (Darmstadt, Germany). Phosphate buffer $\mathrm{pH} 6.8$ solution and potassium dihydrogen phosphate were purchased from Analar (Germany). Hexane, ethyl acetate and methanol were purchased from PT. Brataco Chemika (Bogor, Indonesia). Analytically pure standard of acarbose and $\beta$ sitosterol with purities greater than $99 \%$ were obtained as a gift sample from Dexa Medica labs. (Jakarta, Indonesia).

\section{Instrument}

$\alpha$-glucosidase inhibitory activity was measured using a microplate reader (BioTek model Elx808, USA), an electronic analytical weighing balance (ACIS AW-X Series), an oven (Hotpack54), rotary vacuum evaporator (Buchi model R11, Switzerland) and micropipette, eppendorf, and multichannel pipet (Thermo Scientific).

\section{Extraction and purification}

The dried powder was macerated with hexane at room temperature for $24 \mathrm{~h}$. Hexane extract, then evaporated at the rotary vacuum evaporator to yield condensed residue and the residue was remacerated with ethyl acetate. The obtained filtrate was concentrated under pressure on a rotary vacuum evaporator to yield condensed crude ethyl acetate extract. The ethyl acetate extract was applied to column chromatography (diameter $3.5 \mathrm{~cm}$ ) to separate it into several fractions, each with its specific components. Silica gel G 60 was used as the stationary phase. Meanwhile elution of the extract was done using n-hexane, ethyl acetate and methanol sequentially based on polarity of each solvent. Each fraction was separated on TLC using solvent mixture hexane: ethyl acetate with some comparisons. Fraction with multiple spots were further purified on silica gel G 60 column chromatography (diameter $1 \mathrm{~cm}$ ) and elution with a solvent mixture similarly used in the crude extract elution. The sub fractions of eluent are collected and determined by spotting on TLC with standard compound $\beta$-sitosterol use hexane: acetone $=8: 2$ mobile phase. The plates were air-dried and visualized under UV-Vis light. The similar Rf characteristic was applied to GC-MS to identify the specific active compound.

\section{GC-MS analysis}

The model of the GC-MS was used for mass spectral identification of ethyl acetate sub fraction. The instrument used was an Agilent 19091S433: $325^{\circ} \mathrm{C}: 30 \mathrm{~m} \times 250 \mu \mathrm{m} \times 0.25 \mu \mathrm{m}$. The electron-impact ionization of the mass spectrometry was operated at an electron energy of $70 \mathrm{EV}$. The oven temperature was initially maintained at $80^{\circ} \mathrm{C}$ for $3 \mathrm{~min}$ and then programmed to gradually increase to $250^{\circ} \mathrm{C}$ at $5{ }^{\circ} \mathrm{C}$ min-1. The carrier gas used was helium at $5 \mathrm{ml} / \mathrm{min}$ at flow rate, and $1 \mu \mathrm{l}$ injection volume. The spectrum of the unknown compounds was compared with the spectrum of the component stored in the NIST library. 


\section{Ligand redocking}

The redocking was carried out to the compounds resulted from GCMS. Evaluation parameters of redocking result are $\Delta \mathrm{G}$ and Ki.

\section{In vitro of test $\alpha$-glucosidase inhibitory}

The $\alpha$-glucosidase inhibitory effect of extract and sub fraction was determined according to the standard method [19]. Enzyme solution is $0.15 \mathrm{U} / \mathrm{ml} \alpha$-glucosidase ( $S$. cerevisiae, Sigma-Aldrich, USA) in phosphate buffer ( $\mathrm{pH}$ 6.8) containing $0.2 \%$ bovine serum albumin. Sample solution (ethyl acetate extract and sub fraction B) was prepared by dissolving $100 \mathrm{mg}$ sub fractions in DMSO and diluted with phosphate buffer (pH 6.8) to 50,100, 150, 200 and $250 \mathrm{ppm}$. About $5 \mathrm{mmol}$ pNPG as a substrate in phosphate buffer was added to the mixture to start the reaction. The assay mixture was incubated at $37{ }^{\circ} \mathrm{C}$ for $5 \mathrm{~min}$. Then $17 \mu \mathrm{l}$ enzyme solutions were added and the reaction was incubated at $37{ }^{\circ} \mathrm{C}$ for $15 \mathrm{~min}$ and stopped by adding $100 \mu \mathrm{l}$ of $0.2 \mathrm{M}$ sodium carbonate. As a standard, acarbose was used. The $\mathrm{IC}_{50}$ value was defined as the concentration of $\alpha$-glucosidase inhibitor to inhibit $50 \%$ of its activity under the assay conditions.

\section{RESULTS AND DISCUSSION}

The homology result with a QMEAN Z-score of-0,019 indicates originality of the structure model. The structure predicted exhibited highest scores in terms of stereochemical quality and accuracy, which were $1.60 \AA$ resolution crystal structures [20]. Accuracy of the protein model was generated by PROCHECK. The main chain parameters plotted are Ramachandran plot analysis, while the residues were classified according to their regions of in the quadrangle [21]. The region $87.7 \%$ indicated residues in allowed and $0.2 \%$ was present in disallowed region (accuracy was above 40 $\%)$. The results showed that $\alpha$-glucosidase enzyme was able to recognize a good result for the structure model.

The model of the enzyme is shown in fig. 1

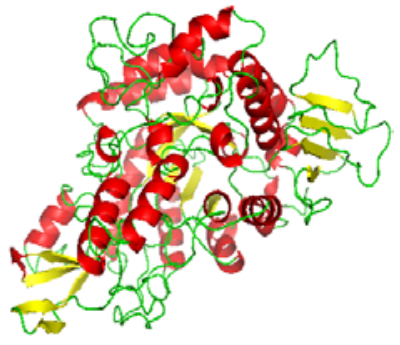

Fig. 1: Model of $\alpha$-Glucosidase enzyme

Points on a 3D grid, placed to cover the entire inner cavity of the molecular surface of $\alpha$-glucosidase $S$. cereviciae. The probe used acarbose, miglitol and voglibose as standards (fig. 2).

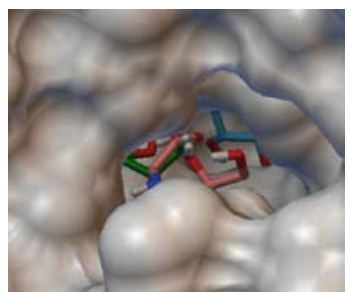

Fig. 2: Molecular surface of $\alpha$-glucosidase $S$. cereviciae showing standards in binding cavity

Note 1b: acarbose (pink), voglibose (blue), miglitol (green)

Result of docking analysis were binding energies and inhibition constant of standards and active compounds in table 2 .

Table 2: Binding energies and inhibition constant

\begin{tabular}{lll}
\hline Standards and active compounds & Binding energy $(\mathbf{k c a l} / \mathbf{m o l})$ & Inhibition constant $(\boldsymbol{\mu M})$ \\
\hline Acarbose & -8.16 & 0.02 \\
Miglitol & -7.72 & 2.23 \\
Voglibose & -6.43 & 67.51 \\
$\beta$-sitosterol & -10.61 & 0.02 \\
Daucosterol & -10.05 & 0.04 \\
1,3,6-tri-O-galoil-D-glucose & -10.33 & 0.03 \\
Corilagin & -9.41 & 0.14 \\
3,6-digaloylgucose & -8.77 & 0.40 \\
$\beta$-glucogaline & -7.60 & 2.94 \\
Ellagic acid & -6.15 & 31.09 \\
Brevifoline & -4.39 & 616.26 \\
Shikimic acid & -4.08 & 1016.67 \\
Gallic acid & -3.41 & 3910.00 \\
Quinic acid & -3.19 & 5230.00 \\
Chebulic acid & -2.26 & 22723.33 \\
Cyanidin-3-0-glycoside & -9.59 & 0.09 \\
\hline
\end{tabular}

As a standard, acarbose has lower binding energy and inhibition constant $(\Delta \mathrm{G}=-8.16 \mathrm{kcal} / \mathrm{mol}, \mathrm{Ki}=0.02 \mu \mathrm{M})$ than miglitol and voglibose. Acarbose as $\alpha$-glucosidase inhibitor, can effectively control blood glucose levels after food intake and have been used clinically in the treatment of diabetes mellitus [22]. $\beta$-sitosterol was shown as the molecule to have the lowest binding energy $(\Delta \mathrm{G}=-10.61 \mathrm{kcal} / \mathrm{mol})$ and inhibition constant $(\mathrm{Ki}=0.02 \mu \mathrm{M})$. Another steroid compound is daucosterol $(\Delta \mathrm{G}=-10.05$ $\mathrm{kcal} / \mathrm{mol}$ and $\mathrm{Ki}=0.04$ ) while 1,3,6-tri-O-galoil-D-glucose is gallotannin $(\Delta \mathrm{G}=-10.33 \mathrm{kcal} / \mathrm{mol}$ and $\mathrm{Ki}=0.03)$. Any compound that is considered to be a better drug candidate should exhibit better drug score (binding energy and inhibition constant) [7]. Based on the docking studies, $\beta$ sitosterol possesses potential as an $\alpha$-glucosidase inhibitor.

The active site surrounding acarbose and $\beta$-sitosterol was visualized and calculated with PyMOL and Ligplot v.4.4.2 [23-24]. Acarbose is surrounded by 18 amino acid residues as its active site: Asp69, Tyr72, Tyr158, Phe159, Phe178, Asp215, Val216, Glu277, Glu279, Phe303,
Asp307, Thr310, Ser311, Arg315, Asp352, Glu411, Arg442, Arg446. In other hand, $\beta$-sitosterol is surrounded by 18 residues: Tyr158, Phe159, Phe178, Asp215, Val216, Glu277, Gln279, His280, Asp307, Arg315, Glu411, Arg442, Phe303, Ser311, Pro312, Leu313, Phe314, Asp352 visualized with PyMOL (fig. 3) and 3D view of the active site of $\beta$-sitosterol from S. cereviciae visualized with Ligplot (fig. 4). Acarbose and $\beta$-sitosterol contain amino and hydroxyl groups. They can form hydrogen bonds with the amino acid residues of the receptor complex. The H-bond interactions and the bond lengths of acarbose and $\beta$ sitosterol was visualized and calculated by PyMOL (fig. 3) and Ligplot (fig. 4). A binding interaction may result in inhibition of the enzyme. Increase in binding energy simultaneous increase in the binding energy [25]. The ability to form hydrogen bond with negatively charged of carbonyl atom in $\beta$-sitosterol with catalytic acid residues creates strong hydrogen bond. There are two H-bonds between $\beta$ sitosterol and Asp215 with bond length 3.04 and $3.05 \AA$. 


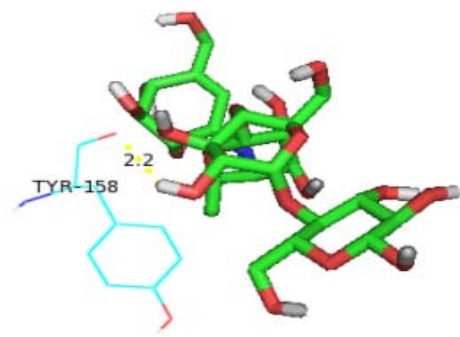

a

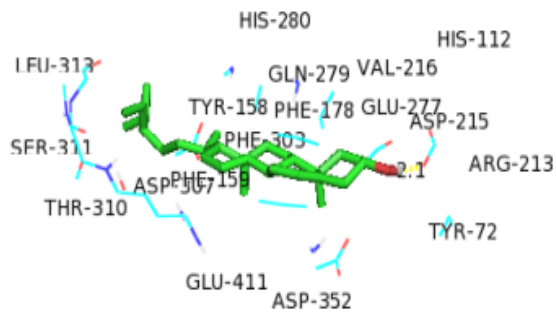

ARG-442

b

Fig. 3: H-bond interactions and bond length of acarbose with Tyr-

158 (a) and $\beta$-sitosterol with Asp-215 (b) visualized in PyMOL

Note fig. 3b: H-bond interactions are spotted in yellow dotted lines

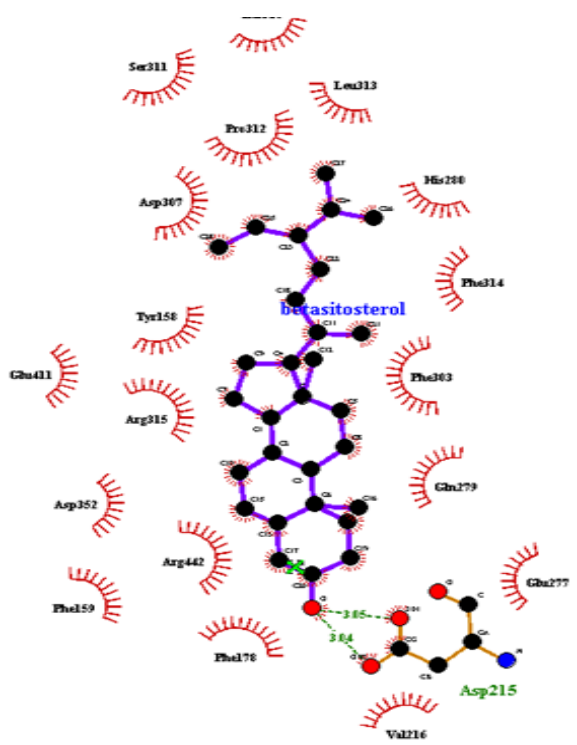

Fig. 4: The Ligplus Visualization showing the hydrogen bond interaction of $\beta$-sitosterol with $\alpha$-glucosidase (the hydrogen bonds represented as a dashed line)

The interaction between ligand and protein binding site was visualized, including hydrogen bond in table 3 .

Table 3: H-bond interactions and bond length obtained for acarbose and $\beta$-sitosterol with PyMOL and LigPlot

\begin{tabular}{llll}
\hline Visualization & Acarbose & & $\boldsymbol{\beta}$-sitosterol \\
\hline & H-Bond interactions & Bond length $(\AA)$ & H-Bond interactions \\
PyMOL & Tyr158 $(\mathrm{O}-\mathrm{OH})$ & 2.20 & Asp215 $(0-0 \mathrm{H})$ \\
LigPlot & Asp215 $(\mathrm{O}-\mathrm{OH})$ & 1.41 & Asp215 $(\mathrm{O}-\mathrm{OH})$ \\
& & & Asp215 $(\mathrm{O}-\mathrm{OH})$ \\
\hline
\end{tabular}

Acarbose and $\beta$-sitosterol contain amino and hydroxyl groups. They can form hydrogen bonds with the amino acid residues of the receptor complex. The ability to form hydrogen bond with negatively charged of carbonyl atom in $\beta$-sitosterol with catalytic acid residues creates strong hydrogen bond. There are two H-bonds between $\beta$-sitosterol and Asp215 with bond length 3.04 and $3.05 \AA$. This docking result showed $\beta$-sitosterol in T. catappa L. fruit as $\alpha$ glucosidase inhibitor in a short time period and reagent-saving manner. $\beta$-sitosterol was found to produce good antidiabetic activity in treated mice. It reversed the weight loss of diabetic mice and restored to normal blood sugar level [26].

\section{Plant material, extraction and purification}

This study, compared to the docking result approaches with extraction and purification of ethyl acetate extract. The result of 83 ethyl acetate fractions of column chromatography gave A, B and C sub fractions. Sub fraction B gave similar spot characteristic and Rf value (0.42) with $\beta$-sitosterol standard.

\section{GC-MS analysis}

Identification of sub fraction B compounds was done using GC-MS based on the retention time, molecular formula, percentage area and molecular mass (table 4). The percentage composition of the ethyl acetate subfraction B constituents was expressed as a percentage of the peak area [27]. They are as $\beta$-sitosterol acetate (stigmast-5-en-3 $\beta$-ol acetate) $2.57 \%$ and sitostenone (stigmast-4-en-3-one) $11.20 \%$. With this result, it was considered that T. catappa L. fruit contains a mixture of $\beta$-sitosterol acetate and sitostenone. They consist of a steroid skeleton as $\beta$ sitosterol. The difference between $\beta$-sitosterol acetate, sitostenone and $\beta$-sitosterol is the substituent present at carbon-3, the presence of carboxylic acid, keto or carbonyl $(\mathrm{C}=0$ ) and hydroxyl groups (fig. 5). The selection of a suitable extraction method and isolation required to isolate the active compound in T. catappa L. fruits.

Table 4: Phytocomponents identified in T. catappa $L$. fruits

\begin{tabular}{llllll}
\hline No & Compound & Rt (min) & Molecular formula & Percentage area & Molecular mass \\
\hline 1 & $\beta$-sitosterol acetate & 36.12 & $\mathrm{C}_{31} \mathrm{H}_{52} \mathrm{O}_{2}$ & 2.57 & 456.74 \\
2 & sitostenone & 39.04 & $\mathrm{C}_{29} \mathrm{H}_{48} \mathrm{O}$ & 11.20 & 412.69 \\
\hline
\end{tabular}

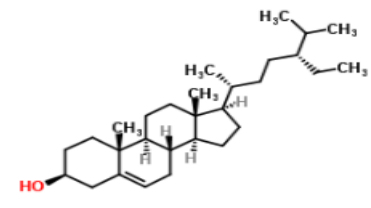

a

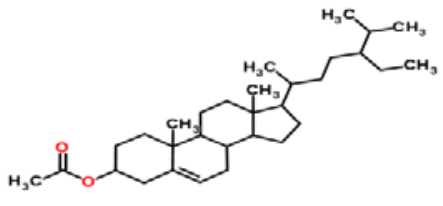

b

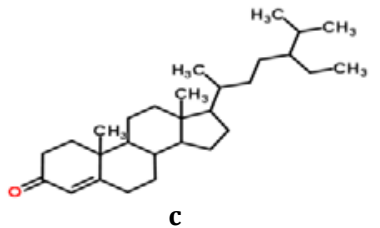

Fig. 5: Chemical structure of $\beta$-sitosterol (a), $\beta$-sitosterol acetate (b), sitostenone (c) 


\section{Ligands redocking from GC-MS result}

Redocking study was performed to find out the $\alpha$-glucosidase affinity for $\beta$-sitosterol acetate and sitostenon. Binding energy of $\beta$ sitosterol acetate $(\Delta \mathrm{G}=-11.14 \mathrm{kcal} / \mathrm{mol})$ is lower than sitostenon $(\Delta \mathrm{G}=-9.79 \mathrm{kcal} / \mathrm{mol})$. The carboxyl group on $\beta$-sitosterol acetate is considered to be a highly polar functional group. The ability to form hydrogen bond with negatively charged of carbonyl atom in $\beta$ sitosterol with catalytic acid residues creates strong hydrogen bond[28]. Based on the redocking result, $\beta$-sitosterol acetate was shown as a potent inhibitor of $\alpha$-glucosidase which the carboxyl group was a highly polar functional group. This review demonstrates the wide use of a computational method for $\alpha$ glucosidase inhibitor discovery and development $\beta$-sitosterol acetate as $\alpha$-glucosidase inhibitor.

\section{In vitro test $\alpha$-glucosidase inhibitory}

Ethyl acetate extract and ethyl acetate sub fraction B was tested in vitro with $\alpha$-glucosidase from $S$. cereviciae. As a standard, acarbose showed strong activity against $\alpha$-glucosidase $\left(\mathrm{IC}_{50}=17.52 \mathrm{ppm}\right)$. Acarbose, nicknamed as "starch blockers", prevent the digestion and absorption of carbohydrates by inhibiting the terminal step of carbohydrate digestion at the brush border of intestinal epithelium. Ethyl acetate extract $\left(\mathrm{IC}_{50}=192.51 \mathrm{ppm}\right.$ ) had higher inhibition than ethyl acetate sub fraction $\mathrm{B}\left(\mathrm{IC}_{50}=296.28 \mathrm{ppm}\right)$. In this study, ethyl acetate extract demonstrated stronger $\alpha$-glucosidase inhibitory activity than ethyl acetate sub fraction B. Extract may be due to the presence of more than one antihyperglycemic principle and their synergistic properties. Inhibitory activity of T. catappa L. fruit ethanol $80 \%$ extract has strong inhibition with $\mathrm{IC}_{50}$ of $3.02 \mathrm{ppm}$. Constituents present in T. catappa L. fruits are structurally inhibitor incorporate with alkaloid, terpen, tannin, saponin and glycoside. Tannin pyrogallol and catechol or catechin in plant may has an effect on the enzyme activity $[4,29]$.

Results of T. catappa in vitro test supported by in vivo test data also compared with another species that is T. belleria and T. superba as anti diabetic. Both of the species have anti-diabetic activity in diabetic animal model induced streptozotocin [30]. It is therefore clear that the effective $\alpha$-glucosidase inhibitory component in this plant is needed to be isolated.

The selection of a suitable extraction method and isolation required to isolate the active compound in T. catappa fruits.

\section{CONCLUSION}

Screening of $\alpha$-glucosidase inhibitor of T. catappa L. fruit use molecular docking and the identification of ethyl acetate subfraction showed three steroids that are $\beta$-sitosterol, $\beta$-sitosterol acetate and sitostenone. The inhibitory activity of ethyl acetate extract is stronger than sub fraction $\mathrm{B}$.

\section{ABBREVIATION}

The authors thank to Faculty of Pharmacy, Universitas Indonesia for supporting this project.

\section{CONFLICT OF INTERESTS}

Declared none

\section{REFERENCES}

1. Sicree R, Shaw J, Zimmet P. The Global Burden. Diabetes and impaired glucose tolerance. Prevalence and Projections. In: Gan D. editor. Diabetes atlas. 3rd ed. Brussels: International Diabetes Federation; 2006. p. 16-103.

2. Olokoba $\mathrm{AB}$, Olusegun $\mathrm{AO}$, Lateefat BO. Type 2 diabetes mellitus: a review of current trends. Oman Med J 2012;27:269-73.

3. Sireesha K, Raghunandan N. Evaluation of in vivo antidiabetic and antioxidant activity of Artocarpus hirsutus seeds in streptozotocin-induced diabetic rats. Asian J Pharm Clin Res 2016;9 Suppl 1:170-2.

4. Mun'im A, Katrin, Azizahwati, Ari A, Kun FM, Maya M. Screening of $\alpha$-glucosidase inhibitory activity of some Indonesian medicinal plants. Int $\mathrm{J}$ Med Arom Plants 2013;3:144-50.
5. Nagappa AN, Thakurdesai PA, Venkat NR, Jiwan S. Antidiabetic activity of Terminalia catappa Linn fruits. J Ethnopharmacol 2003;88:45-50.

6. Meng XY, Hong-Xing, Mihaly M, Meng C. Molecular docking: a powerful approach for structure-baseddrug discovery. Curr Comput Aided Drug Des 2011;7:146-57.

7. Tiwary BK, Pathak RK, Pradhan K, Nanda AK, Bothra AK, Chakraborty R. Evaluation of drug candidature of some quinazoline-4-(3h)-ones as inhibitor of human dihydrofolate reductase enzyme: molecular docking and in silico studies. Int J Pharm Pharm Sci 2014;6 Suppl 2:393-9.

8. Bourne PE, Weissig H. editors. Structural Bioinformatics. New Jersey: Wiley-Liss. Inc; 2003. p. 507-19.

9. Arnold K, Lorenza B, Jurgen K, Torsten S. The SWISS-MODEL Workspace: A web based environment for protein structure homology modelling. Bioinformatics 2003;22:195.

10. Laskowski RA, Mac Arthur MW, Moss DS, Thornton JM. Prochek: aprogram to check the stereochemical quality of protein structures. J Appl Crystallogr 1993;26:283-91.

11. Morris GM, Huey R, Lindstrom W, Sanner MF, Belew RK, Goodsell DS, et al. Autodock4 and AutoDockTools4: automated docking with selective receptor flexiblity. J Computational Chem 2009;16:2785-91.

12. Yamamoto K, HideoM, Masami K, Shigeyoshi O. Crystal structures of isomaltase from Sacharomyces cerevisiae and in complex with its competitive inhibitor maltose. FEBS J 2010;277:4205-14.

13. Sneha JA, Chaudhari S. Alpha-amylase inhibitory and hypoglycemic activity of Clerodendrone multiflorum Linn. Stems. Asian J Pharm Clin Res 2011;4 Issue 2:99-100.

14. Jirawattanapong $\mathrm{W}$, Yenchit $\mathrm{T}$, Thaweephol. Chemical investigation of three kinds of Terminalia Fruits. Bull Dept Med Sci 1997;39:222.

15. Dr Duke's. Phytochemical and Ethnobotanical Databases; 2008. p. 11.

16. Mohale DS, Dewani AP, Chandewar AV, Khadse CD, Tripathi AS, Agrawal SS. Brief review on medicinal potential of Terminalia Catappa. J Herbal Med Toxicol 2009;3:8.

17. Huey R, Garrett MM. Using AutoDock with AutoDock tools: a tutorial. The scripps research Institute Molecular Graphics Laboratory; 2006. p. 7-50.

18. Sundararajan S, Balajee R, Rajan MSD. Comparative docking analysis of neuraminidase with various inhibitors. Int J Pharm Pharm Sci 2010;2 Issue 3:83-5.

19. Elya B, Basah K, Novi FU, Marista GM, Anindita RA. Alfa glucosidase inhibitory activity of Kayu Tuah (Antidesma celebicum MIQ). Int Res J Pharm 2013;4:30.

20. Morris AL, Mac Arthur MW, Hutchinson EG, Thornton JM. Stereochemical quality of protein structure coordinates. Protein 1992;12:345-64.

21. Ramachandran GN, Ramakrishnan C, Sasisekharan V. Stereochemistry of polypeptide chain configurations. J Mol Biol 1963;7:95-9.

22. Yin Z, Wei Z, Fajin F, Yong Z, Wenyi K. $\alpha$-Glucosidase inhibitors isolated from medicinal plants. Food Sci Human Wellness 2014;3:136.

23. PyMOL. Available from: http://www.pymol.org. [Last accessed on 03 Aug 2014].

24. LigPlot. Available from: http://www.ebi.ac.uk/thorntonsrv/software/IIGPLOT. [Last accessed on 03 Aug 2014].

25. Morris GM, Goodsell DS, Halliday RS, Huey R, Hart WE. Automated docking using a Lamarckian genetic algorithm and an empirical free energy function. I Comput Chem 1998;19:1639-62.

26. Karan SK, Sagar KM, Dilipkumar P, Arijit M. Isolation of $\beta$ sitosterol and evaluation of antidiabetic activity of Aristolochia indica in alloxan-induced diabetic mice with a reference to in vitro antioxidant activity. J Med Plants Res 2012;6:1219-23.

27. Hossain MA, Wafa AS Al-Toubi, Afaf MW, Qasim A Al-Riyami, Jamal $\mathrm{N}$ Al-Sabahi. Identification and characterization of chemical compounds indifferent crude extracts from leaves of Omani neem. J Taibah Univ Sci 2013;7:181-8.

28. Hakamata W, Masaaki K, Harunhiro O, Toshiyuki N, Tadatake 0. Design and screening strategies for $\alpha$-glucosidase inhibitors based on enzymological information. Curr Topics Med Chem 2009;9:5-7. 
29. Okuda T, Ito $\mathrm{H}$. Tannins of constant structure in medicinal and food plants hydrolyzable tannins and polyphenols related to tannins. Molecules 2011:16:2191-217.

30. Rupeshkumar M, Kavitha K, Haldar PK. Role of herbal plants in the diabetes mellitus therapy: an overview. Int J Appl Pharm 2014;6:1-3.

\section{How to cite this article}

- Bina Lohita Sari, Abdul Mun'im, Arry Yanuar, Rezi Riadhi. Screening of $\alpha$-glucosidase inhibitors from terminalia catappa L. fruits using molecular docking method and in vitro test. Int J Pharm Pharm Sci 2016;8(12):184-189. 